\title{
Article \\ HBIM for the Characteristics of Korean Traditional Wooden Architecture: Bracket Set Modelling Based on 3D Scanning
}

\author{
Hyun-Chul Youn *, Jun-Seop Yoon * and Seong-Lyong Ryoo *
}

Department of Architecture, Korea University, Anam-ro 145, Seoul 136-713, Korea

* Correspondence: nadaeworld@korea.ac.kr (H.-C.Y.); junsub5120@korea.ac.kr (J.-S.Y.); ryoosl@korea.ac.kr (S.-L.R.)

check for

updates

Citation: Youn, H.-C.; Yoon, J.-S.;

Ryoo, S.-L. HBIM for the

Characteristics of Korean Traditional

Wooden Architecture: Bracket Set

Modelling Based on 3D Scanning.

Buildings 2021, 11, 506. https://

doi.org/10.3390/buildings11110506

Academic Editors: Mislav Stepinac,

Tomislav Kišiček, Ivan Lukačević and Ivan Duvnjak

Received: 5 September 2021

Accepted: 23 October 2021

Published: 26 October 2021

Publisher's Note: MDPI stays neutral with regard to jurisdictional claims in published maps and institutional affiliations.

Copyright: (c) 2021 by the authors. Licensee MDPI, Basel, Switzerland. This article is an open access article distributed under the terms and conditions of the Creative Commons Attribution (CC BY) license (https:// creativecommons.org/licenses/by/ $4.0 /)$.

\begin{abstract}
Historic building information modelling (HBIM) is a technology that documents and analyses 3D model information for reverse engineering using laser scan and image survey data of buildings having heritage value. In the case of traditional Korean wooden architectures, especially the bracket-sets of buildings, there is a limit to accuracy, owing to non-visible seams. Thus, in this study, mesh modelling is conducted using point-cloud data of the entire Seoikheon building of Jeonju Pungpajigwan, which is a national cultural property of Korea. After dismantling the building, scanning the members and cross-checking the cloud data, it was possible to create a realistic Rhino 3D model that includes joints of the bracket set. Hence, it is possible to implement a 3D model in Revit that reflects the unique shapes and characteristics of traditional wooden architectures. The resultant model not only provides a platform of various historic building information, but it can also be used as a digital twin to understand deformation and damage to wooden joints.
\end{abstract}

Keywords: three-dimensional scan; bracket set; historic building information modelling; Korean traditional wooden architecture; reverse engineering

\section{Introduction}

The utilization of modern, innovative technologies to preserve and maintain buildings having cultural heritage has become a global trend. Among these technologies, historic building information modelling (HBIM) performs 3D modelling of buildings based on laser scans and image survey data that allows documentation of the necessary information for analysis [1]. This also results in an informative digital twin of heritage architectures in virtual space via reverse engineering. The representative software is Autodesk Revit, and buildings are designed by integrating various data into the virtual model. The purpose is accurate and efficient reconstruction and maintenance. HBIM also digitizes extant cultural properties using drones and scanners. This allows careful preservation and management. Until now, HBIM studies have been conducted using documentation methodologies focusing on output management. Foremost, the 3D scanning and photogrammetry technology, which is the foundation of HBIM, was developed in the West. Hence, the scope of relevant studies has primarily focused on stone architectures [2-8]. Some HBIMs for wooden structures exist, and the structural analysis aspect is strong with respect to wooden truss analysis, HBIM workflow [9], and storage of life-cycle data about extant timber structures [10]. Additionally, studies [11,12] on the 3D modelling of wooden structures containing various data typically relate to the building spaces rather than detailed cataloguing and wooden-joint methods. Hence, wooden members are secondary to stone configuration in Western studies, and they are often limited to roof trusses and stairs. The 3D analysis of wood is therefore used more for structural stability and shape analysis than wood-to-wood joint methods.

Wooden structures make up a sizeable portion of the cultural architectural properties in East Asia. These countries are now placing extra effort into innovative documentation tasks to help preserve, manage, and utilize traditional wooden structures. Regarding HBIM, 
there have been studies that focused on the modelling process and member methods constituting the wooden structure, and they examined how these members are joined according to the characteristics of traditional East Asian architecture. Cheng et al. created a Revit model of a traditional wooden structure in Taiwan using 3D scan data of a building, including its repair history [13]. By rendering each member of the bracket set into a family component in Revit, this research acquired the flexibility values of various shape modifications [13]. Jiang et al. used Dynamo to research an intelligent automated modelling method for the bracket set of Chinese traditional wooden architectures [14]. Liu et al. sought to reduce errors in the implementation of multiple-levels-of-detail (multi-LoD) parametric models by automatically extracting parameters from the 3D scan data of each member of a bracket set from a traditional Chinese wooden architecture [15]. As such, studies are consistently conducted in the East to secure the efficiency and accuracy of the 3D modelling process based on point-cloud data of wooden members of traditional structures obtained through 3D scanning. Using these approaches, when a digital twin of a cultural property or building is created, building repairs may cause unpredictable degrees of deformation and damage of the joint parts owing to the incomplete digital twin. This is because the aforementioned studies were not performed in a way that accurately identifies the woodto-wood joints, which in fact requires dismantling the traditional wooden structure and scanning each member. Then, after carefully re-assembling the historic structure, other structures can then be estimated based on the learned traditional joint method.

In Korea, the major direction of HBIM for traditional wooden architectures is not only to utilize the precise measurement results obtained from 3D scans, but it is also to integrate and manage previously dispersed information related to cultural properties, such as repair history, into a single 3D model. Because wooden members are more susceptible to deformation and damage than stones with the passing of time, more meticulous documentation is required. Hence, in addition to computer-aided design programs, 3D laser scanners, and computer programs are now used for geometric surveys to accurately document the current appearance of wooden architectures [16]. Since the Cultural Heritage Administration of the Republic of Korea released the original operation guidelines for 3D scanning, it has provided updates via continual revisions to effectively help manage the smart application of 3D scanning technologies to the preservation of cultural heritage sites and to enforce consistent results $[17,18]$. A new study was recently conducted to propose a report-writing method that utilizes 3D scan data to prepare a survey drawing of a traditional wooden structure designated as a cultural property. Research was then performed to suggest a specific configuration system for digital reports instead of paper documents $[19,20]$. Similar to the West, 3D scanning technology is well-utilized with Korean stone architectures. In the case of stone pagodas, a representative stone cultural property of Korean architecture, 3D data for each stage has been documented by performing a 3D scan of each member during dismantling and repair work. The 3D scan data can now be used to examine displacements before and after dismantling [21].

However, for traditional wooden architectures, which account for most Korean cultural properties, 3D modelling is based on existing drawings that are separate from the real-world data of the entire building shape. In the case of Korean traditional wooden architecture, simply obtaining the precise 3D scan data of the structure alone does not make them usable, owing to the characteristics of the joint structures. This raises doubts about the outcomes of such efforts [22], because most studies have not sought to understand well the joint structural characteristics of the traditional wooden architectures, while remaining focused on following extant Western HBIM approaches. Hence, this study aims to investigate the modelling process of the wooden bracket set to determine the important factors of converting 3D scan data of Korean traditional wooden architectures, which are designated as cultural properties, into HBIM data. This study also aims to identify future directions of related studies. 


\section{Materials and Methods}

\subsection{Materials}

Jeonju Pungpaejigwan, located in Jeonju, Jeollabuk-do, Republic of Korea, is estimated to have been built before 1471 during the Joseon Dynasty and is currently designated as Treasure No. 583, a cultural property (Figure 1a). The heritage consists of three parts: Jeongcheong, the central part of the building and the two wings, Seoikheon (west wing) and Dongikheon (east wing). The Seoikheon of the building tilted and there was a leak problem in 2019. Hence, the Cultural Heritage Administration decided to repair it after dismantling it completely; the dismantling work was carried out from April to July 2019. Jeonju Pungpaejigwan uses a wooden joint bracket set called Jusimpo (column-centered bracket), an architectural style that allows the wooden structural unit on the pillars to distribute the weight of the roof (Figure 1b).

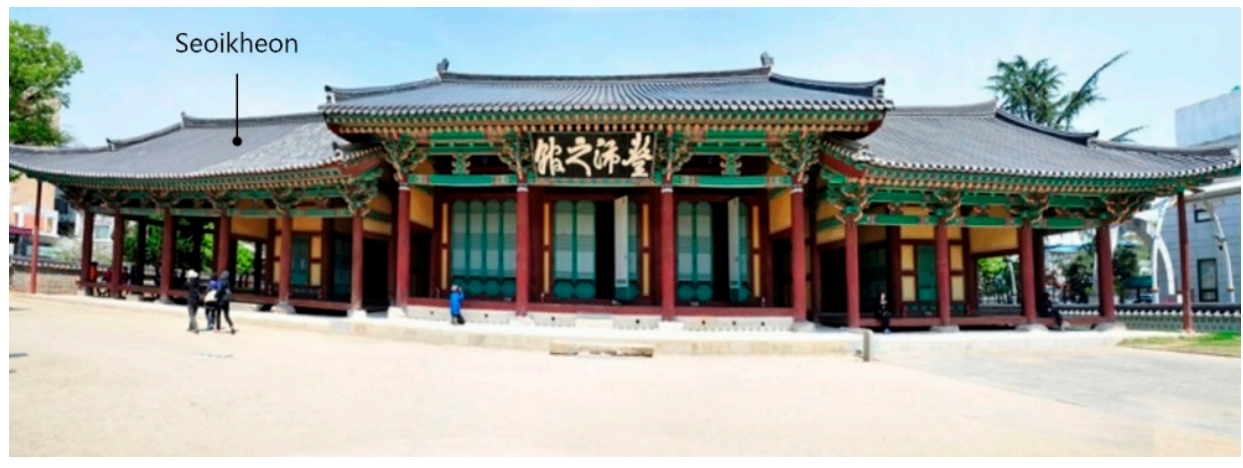

(a)

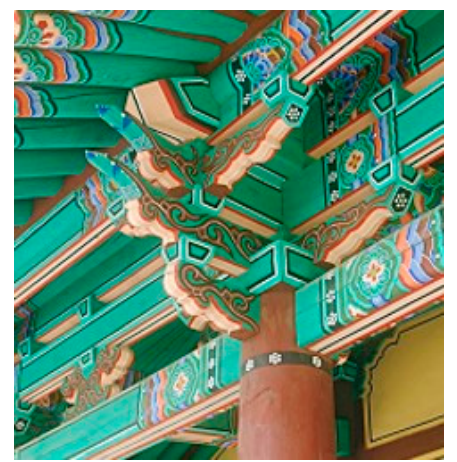

(b)

Figure 1. The material of the research: (a) Jeonju Pungpaejigwan; (b) its Seoikheon's bracket set.

The materials of the study are the bracket set part of Seoikheon (Figure 2a). Bracket sets can be seen in traditional wooden structures not only in Korea, but also in other parts of East Asia. Bracket sets are important architectural elements that have the structural characteristic of transferring the load from the roof of the building to the columns, and they offer decorative characteristics. Furthermore, a bracket set incorporates various shapes of wooden members connected like a puzzle, and it is the most complex architectural element seen in traditional wooden architectures in Asia. Bracket sets are made using the wood-to-wood joint method, which best reveals the skills of the expert carpenters involved. Prior to dismantling the building, it was impossible to see from the outside how the wood-to-wood joints were formed. The shape of the joint between each member can only be checked after dismantling the building. In the case of Seoikheon, the dismantling work was performed during the study. Therefore, it was possible to check the appearance of the dismantled members of the building in addition to the overall shape of the whole. Through this, accurate information about the joints inside the bracket set was obtained.

\subsection{Methods}

This study uses a 3D scan of the entire building before it was dismantled, as well as the 3D scan of the members of Seoikheon that are part of the bracket set part after it was dismantled [23,24]. The existing 3D scanning method of traditional wooden architectures designated as cultural properties uses a wideband 3D scanner to obtain point-cloud data for the entire shape of the building. Recently in Korea, 3D scanning of the entire shape of a cultural property building was performed prior to the start of renovation. However, the scan results were not converted to HBIM. There were limitations in that the 3D scans were intended as promotional materials or diagrams in the repair reports. On the other hand, this study not only obtained point-cloud data by performing exhaustive wideband 3D scanning of the entire building, but it also gained partial 3D mesh data from each 
member by scanning the bracket separately using an Artec Eva precision local scanner (Figure $2 b$ ). The point-cloud data of the entire building were imported into Rhino6 and mesh modelling of the bracket set was conducted based on the morphological information of the cloud. Joint modelling was conducted by checking the scanned form of each wooden member of the bracket set after dismantling the building. Finally, Rhino modelling with morphological information consistent with the actual building was transferred to Revit so that information could be entered for each wooden member. Therefore, this study suggests a use of HBIM suitable for the unique morphological characteristics of Korean traditional wooden architectures that cannot otherwise be clearly recognized from the outside.

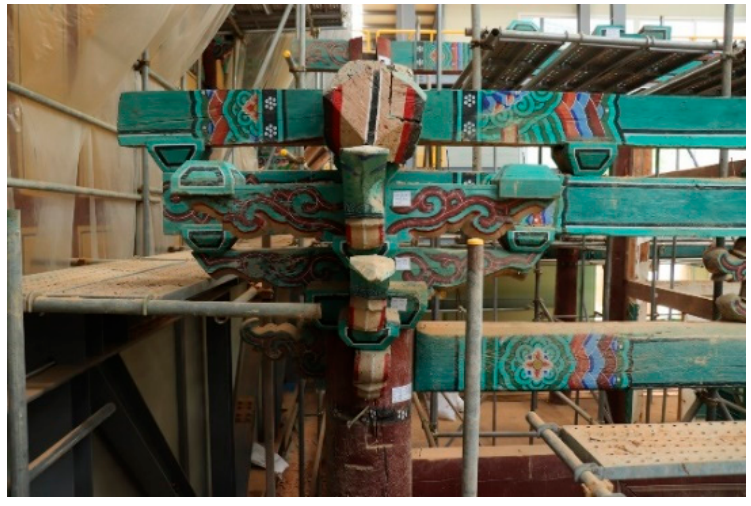

(a)

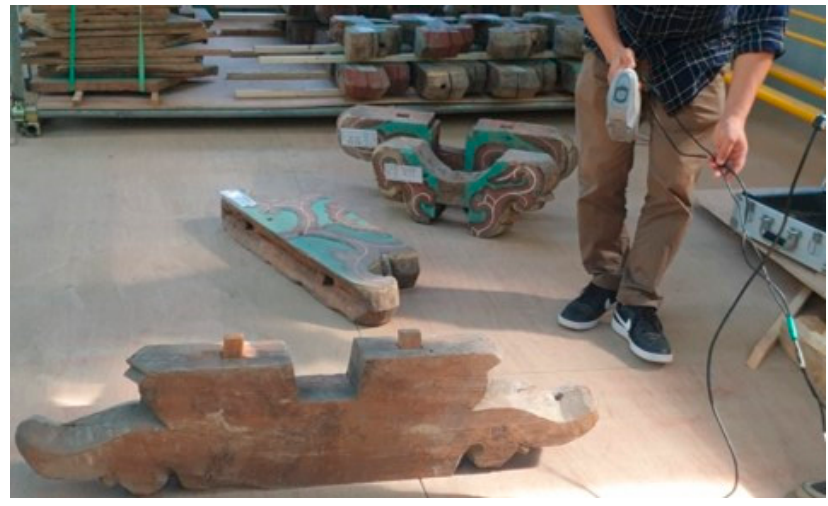

(b)

Figure 2. Three-dimensional scanner is vulnerable to direct sunlight. The renovation of the traditional architecture was carried out by covering the heritage with a temporary steel structure. Therefore, it was possible to scan each member because of the working environment: (a) Dismantling construction of Seo Ik-heon bracket set; (b) three-dimensional scan of each member comprising the Seo Ik-heon bracket set.

The following method was performed based on the scanning data of the entire building before dismantling it and the scanning data of members of the bracket set after dismantling (Figure 3). First, source data were created by using Autodesk Recap to extract only the bracket-set part from the point-cloud data of the 3D scan of the entire building. The mesh modelling of each member of the bracket-set part was performed manually by tracing the point cloud. During this task, the shape of the wooden joint between each member was partially crosschecked with the shape of the members scanned using the Artec Eva scanner. Then, the Rhino 6 modelling file was imported into Autodesk Revit to complete the final HBIM set, which allows the metadata of each component of the bracket set to be entered as though the components were joined to each other. Specifically, the 3DM file for each member in Rhino was converted into a SAT file, and then imported into Revit. Then, in Revit, each mesh member was turned into a family with parameters and stacked in order. The reason for not using the 3D mesh data of Artic Eva for each member as the source data was that the mesh data of each member had too many segments; hence, there was a capacity problem. This research method is slow because it does not utilize an automated process like the studies mentioned earlier. However, it has the advantage of being able to implement the mesh data of the actual shape rather than the estimated shape of the cross-section of the joint between each member of the bracket set [13-15]. On the other hand, the method of this study reveals that there is a limit to the possibility of dismantling and repairing a building. 


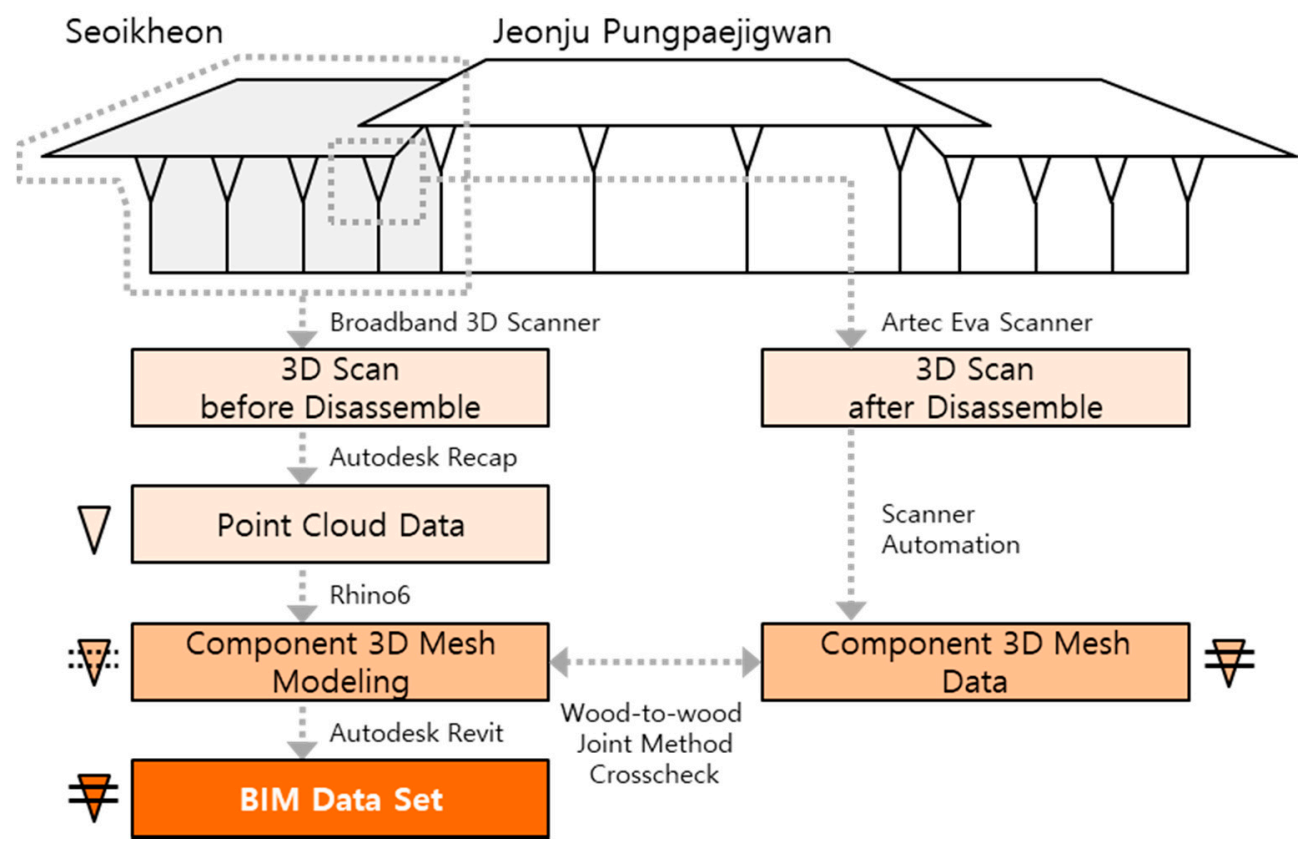

Figure 3. Materials and methods of this research.

\section{Results}

\subsection{From Point Cloud to 3D Mesh Modelling}

In this study, 3D mesh modelling data for each member of the bracket set were generated based on the 3D scan point-cloud data obtained for the Korean traditional wooden architecture. The study was performed by converting 3D mesh modelling data into usable HBIM data. In the case of Korean traditional wooden architectures, the process of converting the point cloud data for an entire building into 3D mesh data divided into each member is difficult to automate using current technologies, and it is difficult to understand how the wooden members are connected with each other based on the external scanning data. In the case of a stone building with a flat cross-section between its members, the computer can recognize the connection areas; hence, it is often possible to automate the splitting of the connection area into single lines. However, the shape of the cross-section is complex and difficult to predict for a wooden building. Therefore, a method that performs the modelling by hand was attempted in this study because Seoikheon was completely dismantled, and the information about the shape of each member of the bracket set was available. The 3D point-cloud data were directly imported into Rhino 6 in this study, and modelling was performed for each member based on it.

When modelling using point-cloud data, errors were corrected to $3 \mathrm{~mm}$ as a criterion to ensure the desired level of accuracy (LoA) of 40 (Figure 4). The carpenters who build traditional wooden structures in Korea use 1 'poon' $(3 \mathrm{~mm})$ as the smallest unit of their work. Hence precision for errors less than $3 \mathrm{~mm}$ were insignificant. Additionally, the Uigwe (construction report) published during the Joseon Dynasty era shows that various measurements ranging from 1 to 9 'poon' were not used. Instead, specific measurements were used for specific buildings. For example, specific measurements, such as 2, 5, 6, and 8 'poon' were mainly used for the Junghwajeon Yeonggeondogam Uigwe bracket sets (Record of Junghwajeon Construction Office) [25]. Hence, 3D modelling was performed in this study with greater accuracy than the errors that could have occurred during the real construction situation. 


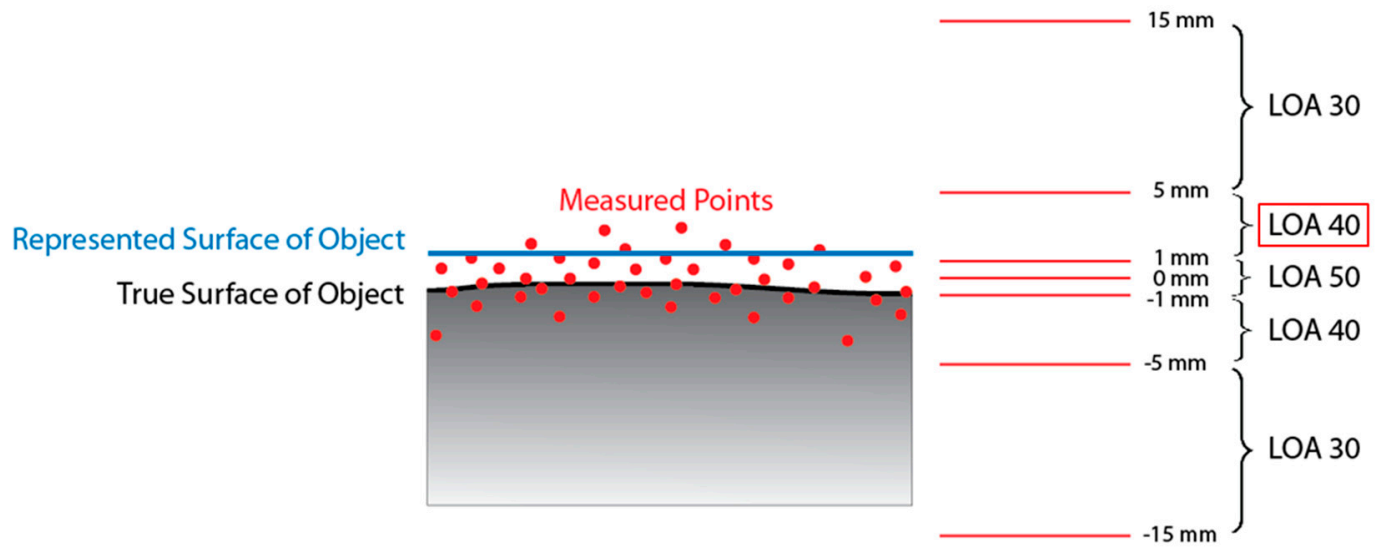

Figure 4. Level of Accuracy (LoA) of three-dimensional modelling. Reprinted with permission from Ref. [26]. Copyright 2016 U.S. Institute of Building Documentation.

Rhino modelling was performed along the boundary shape of the point cloud (Figure 5a). A spline was drawn along the boundary points, and the angle was adjusted so that the drawing would be within the error range mentioned above. When the boundary lines of the members were complete, they were combined to form a side. Thus, it was possible to accurately model the cross-section of the joint between the members. Using the existing documentation method, the morphological appearance of a specific wooden member can be recognized as the same member until it is dismantled. However, in reality the shape of the Soro, a rectangular shape supporter, is changed according to the way other wooden members are joined at its top (Figure 5b). Thus, depending on whether the member atop the Soro has a cross shape or a straight-line shape, the upper part of the Soro is divided into four or two parts. Because such wooden joints comprise the overall shape of the bracket set, this information must be entered into the HBIM model.

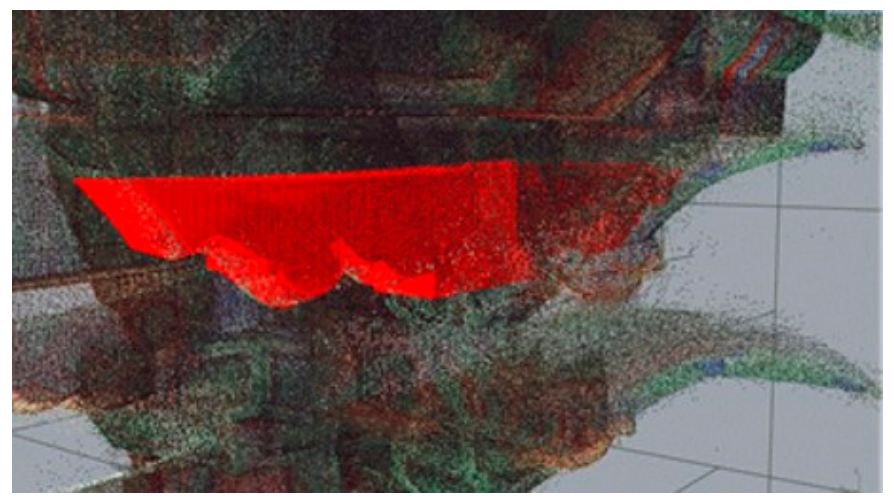

(a)

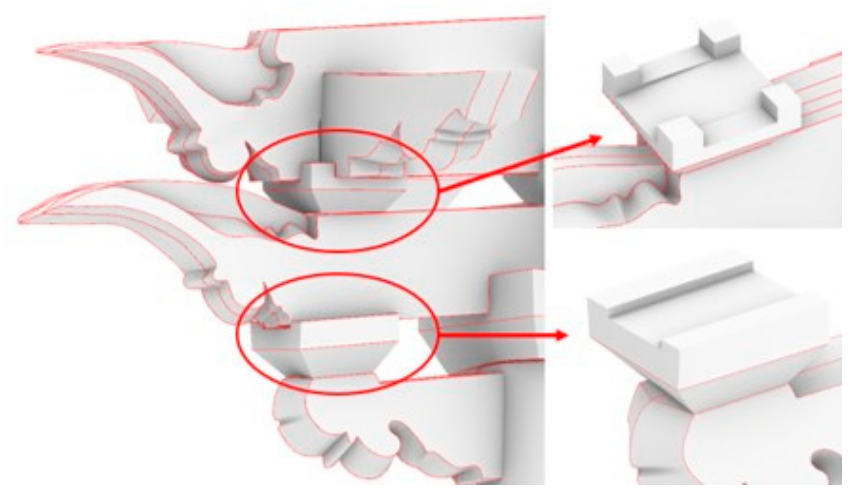

(b)

Figure 5. (a) Rhino modelling process based on the point cloud data; (b) three-dimensional Modelling results consistent with the actual shape of the part.

\subsection{From 3D Mesh Modelling to HBIM Data Set}

Implementation of traditional Korean architecture with HBIM tends to be concentrated in the study of modernization using parametric design methodologies [27] and on the construction of an HBIM library and standardization of each member [28-30]. Even if the bracket set of a cultural property is created in HBIM, the process does not begin from accurate scanning data. Instead, modelling is completed based on extant drawings, photos, and theoretical wood-to-wood joint knowledge [31]. Revit modelling of general buildings has a strong character of standardization, because the family and composition of the 
building is codified, and designs are built according to plans. However, in the case of HBIM, which targets cultural heritage buildings, there is an aspect of customization. Hence, each cultural property must be handled individually via its own digital twin.

Each 3D modelling member was converted to a Revit family with an original name of Korean traditional architecture. The necessary information for each family was connected as a parameter. Therefore, through this modelling, the position, size, type of sculptural form, repair history, and shape of joint of each member can be identified integrally. (Figure 6). Also, the outcome of this study includes a digital twin that can identify the degree of deformation or damage to the wooden joint when the wood is further deformed or damaged in the future. In Korea, many wooden cultural properties have been designated since the 1960s, but they are not managed in an integrated fashion using advanced technology. Therefore, if the HBIM of each cultural property building is implemented in the way that was done in this study, more coordinated management would be possible. Moreover, this HBIM result provides a profound way to visualize what the names of each wooden member are and how they are connected. Therefore, in addition to the technical preservation and management of cultural properties mentioned above, it can be used for public understanding and for educational purposes for students in related fields. Currently, in Korea, information on each cultural property is provided through the National Cultural Heritage Portal of the Cultural Heritage Administration, but the public cannot easily understand the architectural information because they contain only photographs and drawings.

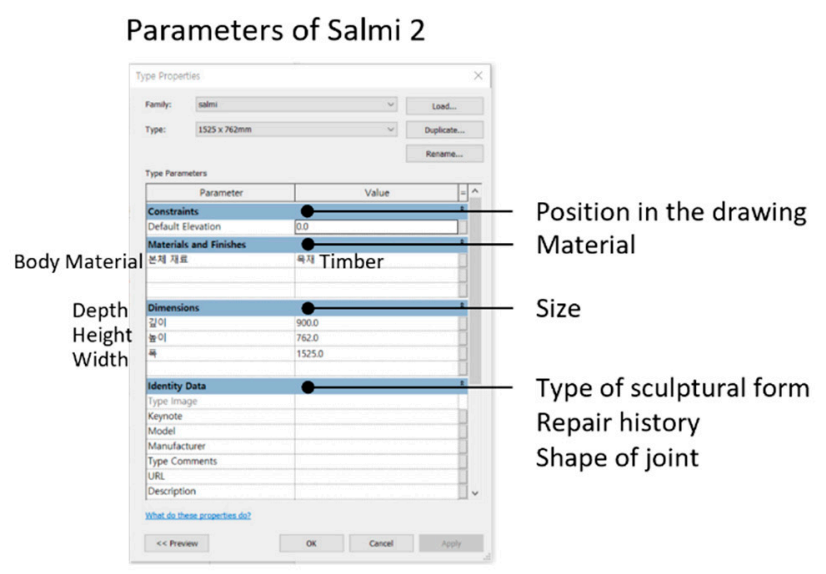

Assembly of the bracket set

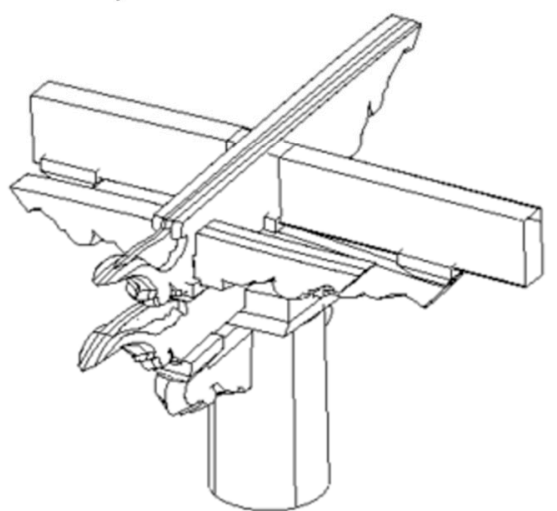

Composition of the HBIM family
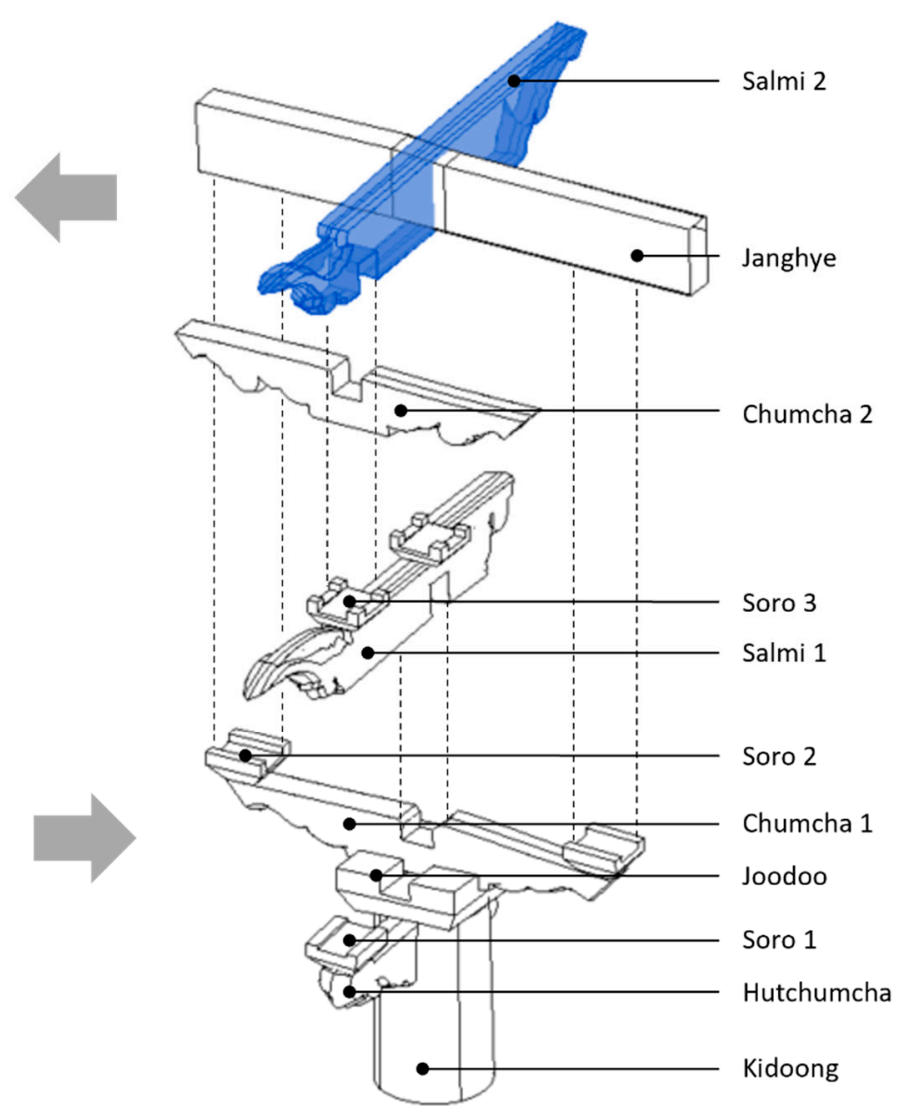

Figure 6. Results of HBIM data set.

\section{Discussion}

The construction methods of classical architecture in the East and the West are similar in that the capital is placed atop of the column, and the transfer part supporting the roof 
structure rests on the capital (Figure 7). In the traditional structures in the East, a bracket set functions as the transfer part and is composed of relatively many members, and the shape of its cross-section is complex. For example, there is a wood-to-wood joint method that cuts out equal portions from the wooden members perpendicular to each other and joins them in a cross shape. The construction method for wooden cultural properties in Korea interlocks and joins the wooden members to maximize the binding force. There are other methods, such as joining wooden members in the same direction. Hence, the characteristic of traditional oriental wooden structures is that they are assembled by carving out the interlocking parts.

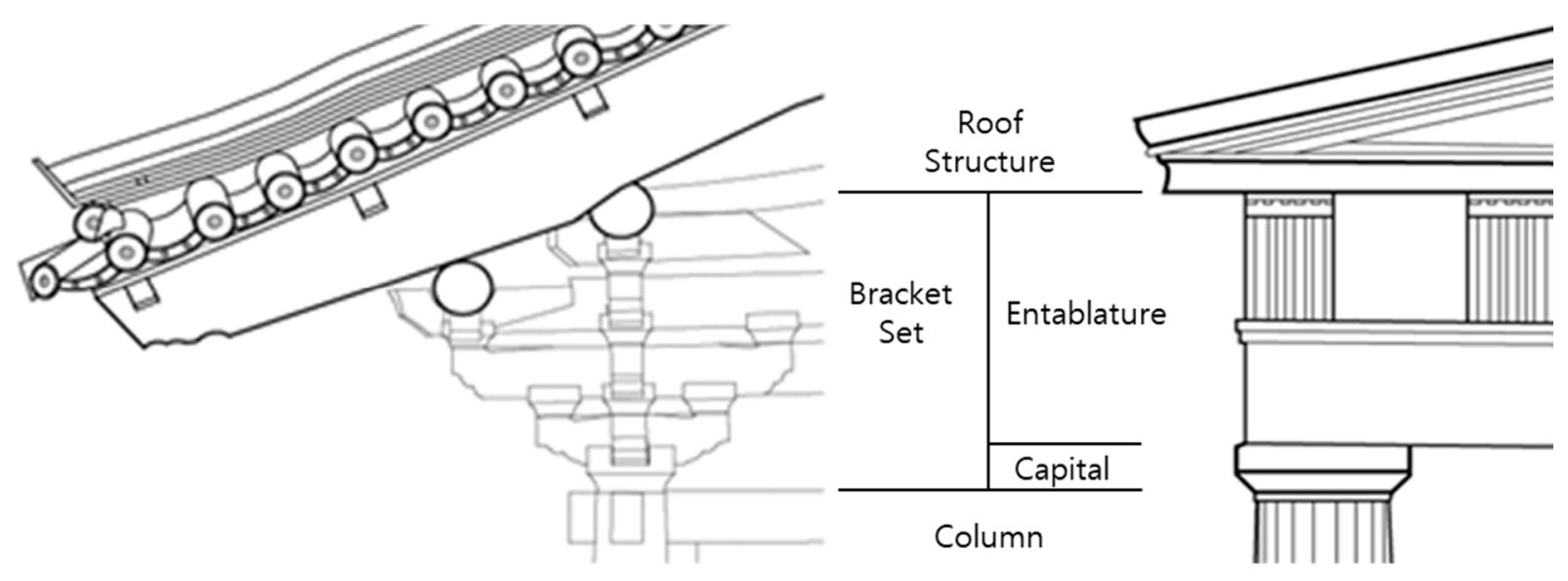

Figure 7. Differences in Eastern and Western classical architecture construction methods.

On the other hand, an entablature set is the transfer part in the West. Here, the members are stacked layer-by-layer and based using compressive force. This difference between the East and the West regarding the transfer part is based on the materials used in buildings. In the wood-centered architectures of the East, a joint system is created by carving out the adjoining parts of the members so that they can be assembled. In the stonecentered architecture of the West, the adjoining parts are made and stacked flat to make it easier to support the weight. Of course, Western temple architectures were initially built using wood, but the building material was later changed to stone. For example, the Greek style comprises parts derived from wood made of columns of tree trunks, diminishing in diameter towards the top. This includes wood beams that support stone entablatures [32]. This can be seen clearly in the Doric Order, where the Mutule and Triglyph are major examples [33]. Although Eastern architecture has continually developed member-type assembly structures, such as bracket sets centering around wood, Western architecture has developed integrated curved structures, such as arches and domes, centering around stones.

Using the method of creating point cloud data by scanning an entire building, a significant difference occurs when the data are meshed for use in HBIM and separated by components, owing the aforementioned characteristics of architectures in the East and the West (Figure 8). First, in the modelling file of Western classical architecture, between the members can be easily trimmed because the shape of the cross-section among the connected components, such as cornerstone, column, capital, entablature, and roof structure, is relatively flat. Therefore, there is no significant problem with splitting in programs such as Rhino 6 or Autodesk Revit. On the other hand, in the case of the wooden structures in the East, it is not a simple task to separate out the members constituting the bracket set composed of a single mesh. This is because it is impossible to find out from the 3D scan data how each part is joined with other parts in a wooden structure where the members are joined in an interlocking manner. For example, even in the case of the 'Banteog Majchum method (A method of cutting and fitting the meeting parts of the 
members in half each)', which is the simplest joint method in traditional architecture of Korea, it is impossible to determine based only on the scan data whether there is one or two members combined. Even if it is thought that a member is clearly overlapped with other members, they can be joined in many ways. The number of ways these members overlap increase exponentially if the joint method cannot be confirmed as the 'Banteog Majchum method'. No matter how complexly connected within an object, the current scan technology recognizes it as a single point cloud mass, and there is no function to separate each component (Figure 9).

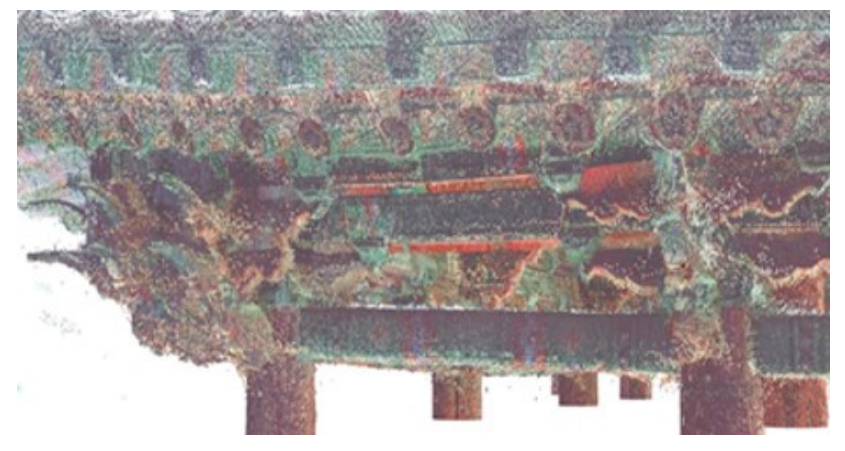

(a)

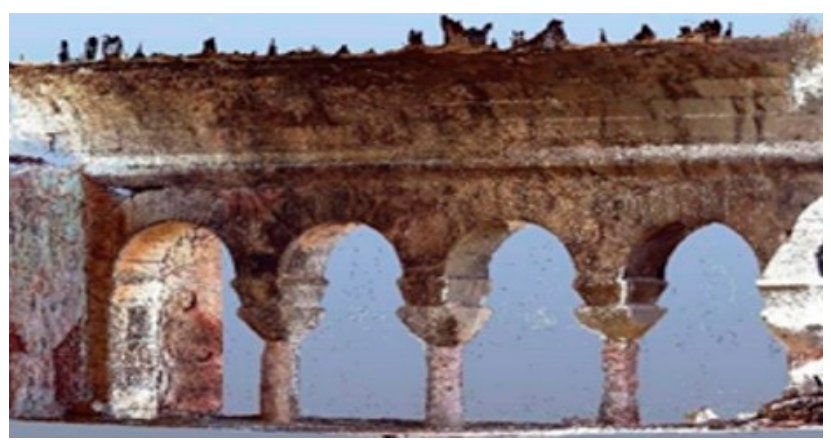

(b)

Figure 8. Three-dimensional scanning point-cloud data: (a) Jeonju Pungpaejigwan (subject of the study). This building shows the complex joint structure of traditional wooden buildings that exist in the East.; (b) The cistern of Hagia Thecla Basilica. This arch-structured building shows the characteristics of Western classical architecture. It is relatively possible to predict the shape of the coupling between the members. Reprinted with permission from Ref. [34]. Copyright 2016 The Open Construction \& Building Technology Journal.

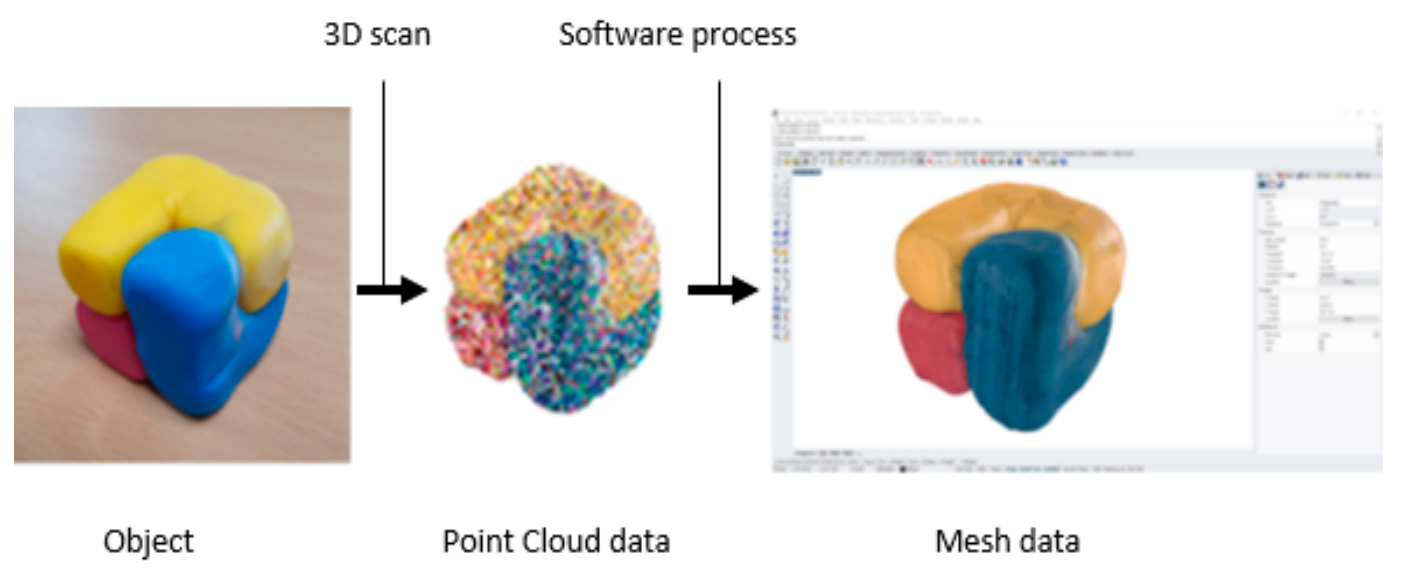

Figure 9. The notion of full scanning method where the internal connection structure is unknown.

Ultimately, the most ideal way of compiling HBIM data for traditional wooden structures in the East based on the 3D scan data is to dismantle the building and perform a 3D scanning of all wooden members. If the capacity of the mesh data containing the shape information of each member is optimized by adjusting the number of surfaces, and the members are assembled in a digital space, the outcome could provide a perfect digital twin of a building that exists in the real world. It would also provide an HBIM model that contains the metadata of each member of the structure. However, if it is not possible to dismantle the building, the process of creating a digital twin of traditional wooden structures, which are designated as cultural properties, requires the intervention of experts who know the 'techniques used by the carpenters of that time'. 


\section{Conclusions}

In the case of Western stone heritage architectures, there is no problem utilizing captured 3D data, even if the building is not dismantled. This is because it is easy to predict the joints among members based on widespread modern use. However, in the case of historic Korean wooden structures with joint bracket sets, there is a limit to realizing a complete HBIM, even by 3D scanning the entire building. This is because the joints use a complex connection method among the wooden members that cannot be visually inspected in situ. Hence, until now, the unique morphological characteristics of wooden cultural properties cannot be perfectly created in the digital space. This has sometimes required an expert in the historical architectural trade to take part. In this study, after dismantling the target building, a 3D scan of each member was performed. Then, it was compared with the 3D scan data of the entire building, and modelling was conducted based on the criteria that fit the actual construction variables. Thus, we implemented an HBIM model suitable for the entire building shape. With our solution, other historic architectural heritage buildings in Korea can now benefit from an improved model embedded with ground-truth information on the wooden joint brackets.

Author Contributions: All authors contributed substantially to this study. Individual contributions include conceptualization, J.-S.Y. and S.-L.R.; methodology, H.-C.Y.; validation, H.-C.Y. and S.-L.R.; formal analysis, J.-S.Y. and S.-L.R.; investigation, H.-C.Y. and S.-L.R.; resources, H.-C.Y. and J.-S.Y. and S.-L.R.; data curation, H.-C.Y. and S.-L.R.; original draft preparation, H.-C.Y. and S.-L.R.; review and editing, S.-L.R.; and visualization, H.-C.Y. and J.-S.Y. All authors have read and agreed to the published version of the manuscript.

Funding: This research received no external funding.

Conflicts of Interest: The authors declare no conflict of interest.

\section{References}

1. Murphy, M.; McGovern, E.; Pavia, S. Historic building information modelling (HBIM). Struct. Surv. 2009, 27, 311-327. [CrossRef]

2. Khodeir, L.M.; Aly, D.; Tarek, S. Integrating HBIM (Heritage Building Information Modelling) tools in the application of sustainable retrofitting of heritage buildings in Egypt. Proc. Environ. Sci. 2016, 34, 258-270. [CrossRef]

3. Quattrini, R.; Pierdicca, R.; Morbidoni, C. Knowledge-based data enrichment for HBIM: Exploring high-quality models using the semantic-web. J. Cultur. Herit. 2017, 28, 129-139. [CrossRef]

4. Brumana, R.; Oreni, D.; Raimondi, A.; Georgopoulos, A.; Bregianni, A. From survey to HBIM for documentation, dissemination and management of built heritage: The case study of St. Maria in Scaria d'Intelvi. In Proceedings of the 2013 Digital Heritage International Congress (Digital Heritage), Marseille, France, 28 October-1 November 2013; Volume 1, pp. 497-504.

5. $\quad$ Brumana, R.; Della Torre, S.; Previtali, M.; Barazzetti, L.; Cantini, L.; Oreni, D.; Banfi, F. Generative HBIM modelling to embody complexity (LOD, LOG, LOA, LOI): Surveying, preservation, site intervention一the Basilica di Collemaggio (L'Aquila). Appl. Geomat. 2018, 10, 545-567. [CrossRef]

6. Megahed, N.A. Towards a theoretical framework for HBIM approach in historic preservation and management. ArchNet-IJAR: Int. J. Archit. Res. 2015, 9, 130. [CrossRef]

7. Chiabrando, F.; Sammartano, G.; Spanò, A. Historical buildings models and their handling via 3D survey: From points clouds to user-oriented HBIM. Int. Arch. Photogram. Remote Sens. Spat. Inform. Sci. 2016, 41, 633-640. [CrossRef]

8. Yang, X.; Lu, Y.C.; Murtiyoso, A.; Koehl, M.; Grussenmeyer, P. HBIM modelling from the surface mesh and its extended capability of knowledge representation. ISPRS Int. J. Geo-Inform. 2019, 8, 301. [CrossRef]

9. Massafra, A.; Prati, D.; Predari, G.; Gulli, R. Wooden truss analysis, preservation strategies, and digital documentation through parametric 3D modeling and HBIM workflow. Sustainability 2020, 12, 4975. [CrossRef]

10. Mol, A.; Cabaleiro, M.; Sousa, H.S.; Branco, J.M. HBIM for storing life-cycle data regarding decay and damage in existing timber structures. Autom. Construc. 2020, 117, 103262. [CrossRef]

11. Sztwiertnia, D.; Ochałek, A.; Tama, A.; Lewińska, P. HBIM (Heritage building information model) of the Wang Stave Church in Karpacz-Case study. Int. J. Archit. Herit. 2021, 15, 713-727. [CrossRef]

12. Brusaporci, S.; Luigini, A.; Vattano, S.; Maiezza, P.; Tata, A. AHBIM for Wooden Built Heritage Conservation. In Digital Wood Design; Springer: Cham, Switzerland, 2019; pp. 533-546.

13. Cheng, Y.M.; Kuo, C.L.; Mou, C.C. Ontology-based HBIM for historic buildings with traditional woodwork in Taiwan. J. Civ. Eng. Manag. 2021, 27, 27-44. [CrossRef]

14. Jiang, Y.; Li, A.; Xie, L.; Hou, M.; Qi, Y.; Liu, H. Development and application of an intelligent modeling method for ancient wooden architecture. ISPRS Int. J. Geo-Inform. 2020, 9, 167. [CrossRef] 
15. Liu, H.; Xie, L.; Shi, L.; Hou, M.; Li, A.; Hu, Y. A method of automatic extraction of parameters of multi-LoD BIM models for typical components in wooden architectural-Heritage structures. Adv. Engin. Inform. 2019, 42, 101002. [CrossRef]

16. Shabani, A.; Kioumarsi, M.; Plevris, V.; Stamatopoulos, H. Structural Vulnerability Assessment of Heritage Timber Buildings: A Methodological Proposal. Forests 2020, 11, 881. [CrossRef]

17. Ham, N.; Bae, B.; Yuh, O. Phased Reverse Engineering Framework for Sustainable Cultural Heritage Archives Using Laser Scanning and BIM: The Case of the Hwanggungwoo (Seoul, Korea). Sustainability 2020, 12, 8108. [CrossRef]

18. Cultural Heritage Administration. Standard Operation Guidelines for 3D Laser Scanning of Cultural Heritage; CHA: Deajun, Korea, 2012.

19. Cultural Heritage Administration. Guidelines for Building Cultural Heritage 3D Scan Data; CHA: Deajun, Korea, 2018.

20. An, D. The Concept and Limitation for Practical Use of 3D Scan Data for the Survey Report of Wooden Architectural HeritageFocused on Survey Drawings. J. Archit. Inst. Korea Plan. Des. 2013, 29, 141-149.

21. Jun, B.; Han, B. Three-dimensions digital documentation and use of Three storied stone pagoda in Mulgeol-ri, Hongcheon. Conserv. Stud. 2014, 35, 99-110.

22. An, D. The Study on Description about Application of 3D Scan data for the Survey Report of Wooden Architectural Heritage. J. Archit. Inst. Korea Plan. Des. 2015, 31, 65-74. [CrossRef]

23. Yoon, J.-S.; Ryoo, S.-L. A Study on the Advancement of Wooden Cultural Heritage Documentation through 3D Scanning. J. Archit. Inst. Korea 2020, 36, 97-105.

24. Yoon, J.-S. A Study on the Implementation and Utilization of BIM for Wooden Cultural Heritage 3D Scan Data. Master's Thesis, Korea University, Seoul, Korea, August 2020.

25. Sung, K.H. Junghwajeon Yeonggeondogam Uigwe [Record of Junghwajeon Construction Office]; Yeonggeondogam: Hanseongbu, Korean, 1907; (National Palace Museum of Korea Possession)

26. USIBD Level of Accuracy (LOA) Specification Guide; U.S. Institute of Building Documentation: Tustin, CA, USA, 2016 ; p. 10.

27. Park, J. BIM-based parametric design methodology for modernized Korean traditional buildings. J. Asian Archit. Build. Eng. 2011, 10, 327-334. [CrossRef]

28. Park, J.D.; Kim, J.Y. A Study on the categorization system of the BIM-library for wooden structure of the Korean traditional buildings. J. Archit. Inst. Korea Struct. Constr. 2012, 28, 119-126.

29. Kim, I.H.; Park, S.H.; Lee, J.A. A Framework of the Open BIM-based Integrated Information System for the Korean Traditional House. J. Archit. Inst. Korea Plan. Des. 2012, 28, 13-20.

30. Kim, I.H.; Jin, J.; Seo, J.C.; Kim, K.S. Development of an Open BIM-Based Korean Traditional House Component Library Using an XML Parametric Information Approach. Archit. Res. 2011, 13, 11-18. [CrossRef]

31. Park, S.H.; Ahn, E.Y. Understanding of the Sung-Rye-Moon Roof Structure and implementation of the traditional Bracket-set Design Modules for BIM tools. J. Korea Multimed. Soc. 2011, 14, 1613-1620. [CrossRef]

32. Gardiner, S.; Varnoux, H. Introduction to Architecture; Bounty Books: London, UK, 1993; pp. $20-21$.

33. Rowland, I.D.; Howe, T.N. (Eds.) Vitruvius: Ten Books on Architecture; Cambridge University Press: Cambridge, UK, 2001.

34. Almac, U.; Pekmezci, I.P.; Ahunbay, M. Numerical analysis of historic structural elements using 3D point cloud data. Open Constr. Build. Technol. J. 2016, 10, 239. [CrossRef] 